\title{
Efek Penurunan Tahanan Pembumian Tower 150 kV Terhadap Sistem Penyaluran Petir
}

\author{
Naomi Lembang ${ }^{*}$, Salama Manjang ${ }^{1}$, Ikhlas Kitta ${ }^{1}$ \\ ${ }^{1}$ Departemen Teknik Elektro, Fakultas Teknik, Universitas Hasanuddin \\ Jl. Poros Malino Km.6, Bontomarannu, Gowa, Sulawesi Selatan, 92171, Indonesia \\ *Email: naomi_lembang@ymail.com
}

\begin{abstract}
Abstrak
Telah terjadi gangguan di sistem transmisi SULSELRABAR mengakibatkan terjadinya black out pada hari selasa 19 Januari 2016 pukul 14.13 WITA. Gangguan tersebut terjadi bersamaan dengan hujan dan angin kencang disertai petir yang begitu keras menyebabakan lepasnya beban sebesar 746 MW menimbulkan kerugian PLN sebesar Rp. 8.355.200.000. Penelitian ini bertujuan untuk mengetahui dan menganalisa dampak terjadinya back flashover yang mempengaruhi jaringan $150 \mathrm{kV}$ akibat surja petir di lingkungan tropis, mengetahui dan menganalisa besar tegangan impuls dijaringan transmisi $150 \mathrm{kV}$ akibat back flashover, dan mengetahui solusi yang paling efektif mengurangi surja petir.Dari hasil penelitian ini efek nilai pentanahan akibat sambaran petir di sistem jaringan transmisi $150 \mathrm{kV}$ khususnya di sepanjang line transmisi GI Sungguminasa - GI Tallasa berdampak pada kerusakan peralatan gardu induk dan pemadaman meluas. Untuk menganalisis hal tersebut digunakan metode simulasi ATPdraw, metode gelombang berjalan dan metode paralelisasi guna menemukan dampak back flashover pada setiap nilai pentanahan tower. Respon terhadap nilai pentanahan tiap tower, terdapat 41 tower berdampak terjadi loncatan api balik sudah melebihi BIL isolator. Hasil penelitian ini menujukkan penurunan nilai pentanahan metode paralelisasi menggunakan tembaga penambahan arang dan garam dapat mereduksi besarnya nilai pentanahan senilai $0,78 \mathrm{ohm}$, dapat mempengaruhi kestabilan sistem saat terjadi sambaran petir.
\end{abstract}

\begin{abstract}
There has been a disturbance in the transmission system SULSELRABAR resulted in the black out on Tuesday, January 19, 2016 at 14:13 WITA. The disruption occurred along with the rain and strong winds accompanied by lightning so loud that the burden of $746 \mathrm{MW}$ caused PLN losses of Rp. 8,355,200,000. This study aims to determine and analyze the impact of back flashover affecting $150 \mathrm{kV}$ network due to lightning surge in tropical environment, to know and analyze the impulse voltage in $150 \mathrm{kV}$ transmission due to back flashover, and to know the most effective solution to reduce lightning surge. From the results of this study the effect of the grounding value due to lightning strikes in the transmission network system of $150 \mathrm{Kv}$ especially along the transmission line GI Sungguminasa - GI Tallasa affect the damage of substation equipment and widespread black out. To analyse the metter, ATPdraw simulation method, current wave method, and parallelization method were used to find out the back flashover impact of every tower grounding value. Response to the grounding value of every tower. There are 41 towers affected by the fire flip having exceeded BIL isolator. The research result indicates that the grounding value decrease of the parallelization method using the charcoal additional copper and salt can reduce the grounding value magnitude of $0.78 \mathrm{ohm}$ and can influence the system stability during the lightning strike occurrence.
\end{abstract}

Kata-kunci: Pentanahan, ATPdraw, Gelombang Berjalan, Metode Paralelisasi, Back flashover.

\section{Pendahuluan}

Sambaran petir merupakan ancaman yang sangat serius dalam sistem tenaga listrik di mana jaringannya tersebar luas gangguan bagi transmisi yang mengakibatkan kerugian besar pada penyedia layanan kelistrikan [1]. Pada jaringan saluran transmisi $150 \mathrm{kV}$, gardu induk Indonesia terdapat permasalahan kerusakan peralatan akibat sambaran petir yang langsung menyambar kawat tanah dan menara. Pada saat tegangan melebihi atau sama dengan tegangan batas kristis lompatan api pada isolator sehingga terjadi fenomena BFO (Back Flash Over).

Sehingga menimbulkan bentuk gelombang impuls karena naiknya tegangan pada jaringan transmisi sampai ke ujung jaringan pada gardu induk yang dapat merusak isolasi. Oleh karena 
itu yang perlu di lakukan adalah penelitian tentang kinerja jaringan transmisi $150 \mathrm{kV}$ akibat sambaran petir menggunakan ATPDraw. ATP telah digunakan untuk mempelajari kinerja jalur transmisi petir [2]. Untuk memperoleh profil tegangan akibat tegangan lebih atau sama dari batas kristis lompatan api pada isolator, atau hasil arus menggunakan perangkat ATPDraw, hasil kondisi titik BFO yang terjadi pada suatu menara transmisi $150 \mathrm{kV}$ Sungguminasa-Tallasa dan menggunakan teori gelombang berjalan untuk menghitung gangguan kilat pada menara, yaitu gangguan karena lompatan api balik back flaschover). Karena pantulan gelombang berjalan yang terbentuk oleh sambaran petir, di mana pantulan dari dasar menara akan tiba lebih cepat di menara atas kemudian refleksi dari menara yang berdekatan [3].

Agar mengurangi kemungkinan terjadinya pemadaman dan kerusakan peralatan transmisi akibat BFO, maka dilakukan dengan cara menurunkan nilai pentanahan yang kondisi ketahanannya dalam waktu jangka panjang. Dilakukan pada titik terjadinya BFO pada menara transmisi Sungguminasa-Tallasa.

Untuk menurunkan nilai pentanahan maka digunakan batangan tembaga pentanahan (arde) dengan ditanahkan di bawah permukaan tanah sedalam 4.20 meter dengan metode paralelisasi dekat tiang menara dan penambahan $\mathrm{NaCl}+\mathrm{C}$ (garam+arang) dengan mengukur pentanahan menggunakan metode paralelisasi. penghubung konduktor Sistem grounding dari saluran listrik ke air garam bisa mengurangi secara simultan grounding impedance. Kenaikan tegangan melebihi batas keamanan bisa dikembangkan sebuah kontra terus-menerus, terhubung ke air asin bisa menstabilkan potensial profil [4].

Perbandingan penambahan garam dan bentonit terhadap nilai pentanahan menggunakan tipe rod untuk menurunkan nilai pentanahan [5].

Sehingga hasil pengaruh besaran pembumian ini kedepannya diharapkan dapat menjadi pertimbangan untuk mengurangi kerusakan peralatan saluran transmisi pada gardu induk $150 \mathrm{kV}$ akibat dari sambaran surja petir.

\section{Landasan Teori}

\subsection{Tegangan Impuls}

Tegangan impuls di definisikan sebagai suatu gelombang yang berbentuk eksponensial ganda yang dapat dinyatakan dengan persamaan:

$$
(t)=V o e-a t-e-b t
$$

Di sisi lain, sekitar $30 \mathrm{~m}$ dari dasar menara (yaitu terkonsentrasi sistem grounding menara), impedansi grounding menara hanya menunjukkan ketergantungan saat ini, yang dapat dimodelkan sesuai dengan pedoman yang diberikan [6] dan diterapkan pada perangkat lunak EMTP-ATP Paket dengan menggunakan model bahasa.

Model analisa sambaran petir line transmisi $150 \mathrm{kV}$ disimulasikan dengan menggunakan software ATPDraw. Pemodelan line transmisi yang digunakan pada simulasi ini adalah dengan menggunakan data historikal gangguan sambaran petir yang pernah terjadi pada saluran transmisi $150 \mathrm{kV}$ khususnya di line transmisi GI Sungguminasa dan GI Tallasa pada tanggal 19 Januari 2016.

Saluran transmisi sistem kelistrikan khusunya di Tragi Bulukumba membawahi GI Sungguminasa, GI Takalar, GI Jeneponto dan GI Bulukumba yang terinterkoneksi terletak di jalur antara laut dan gunung yang memiliki banyak awan cumulonimbus yang menghasilkan petir. tulisan ini menyajikan analisis sensitivitas petir kinerja transmisi dengan menggunakan ATP [7].

Sumber tegangan dimodelkan oleh ATP model AC3ph (sumber 3 fasa). Sumber tegangan AC dalam software ATPDraw digunakan puncak amplitudo sistem tegangan [8]. Pemodelan sumber tegangan AC dapat dilakukan dengan mengkonversi sistem tegangan $150 \mathrm{kV}_{\mathrm{L}-\mathrm{L} \text { (RMS) }} \mathrm{ke}$ puncak tegangan Vpeak $=\sqrt{2} / \sqrt{3} \times \mathrm{V}_{\mathrm{L}-\mathrm{L}}$ (RMS) .

Transformator dimodelkan oleh komponen trafo ideal 3 fasa dengan perbandingan tegangan primer dan sekunder $150 \mathrm{kV} / 20 \mathrm{kV}=7,5$. Sesuai yang terpasang di lapangan, grup transformator Yy Beban $20 \mathrm{kV}$ yang terhubung ke masingmasing trafo dimodelkan dalam software ATPDraw menggunakan komponen RLcY3. Berikut ini adalah rata-rata presentase beban 
setiap tranformator yang terpasang dapat dilihat pada Tabel 1.

Tabel 1. Kapasitas dan beban transformator terpasang pada line transmisi tragi Bulukumba

\begin{tabular}{|c|c|c|c|}
\hline No. & Gardu Induk & $\begin{array}{c}\text { Kapasitas } \\
\text { Terpasang } \\
(\mathrm{MVA})\end{array}$ & $\begin{array}{c}\text { Beban } \\
\%\end{array}$ \\
\hline 1 & Sungguminasa & 60 & 46 \\
\hline 2 & \multirow{2}{*}{ Tallasa } & 20 & 12 \\
\hline 3 & & 30 & 16 \\
\hline 4 & \multirow{2}{*}{ Jeneponto } & 20 & 8 \\
\hline 5 & & 30 & 12 \\
\hline 6 & \multirow{2}{*}{ Bulukumba } & 20 & 17 \\
\hline 7 & & 30 & 26 \\
\hline
\end{tabular}

Beban pada simulasi ini dimodelkan dengan menggunakan komponen RLcY3 dengan menggunakan Persamaan:

$$
\begin{gathered}
R=\sqrt{3} \frac{V^{2}}{P} \\
L=\sqrt{3} \frac{V^{2}}{(2 \pi f Q)}
\end{gathered}
$$

\subsection{Tegangan pada gangguan (BFO)}

Sambaran pada kawat tanah atau menara menyebabkan terjadinya kenaikan tegangan yang dapat menyebabkan terjadinya BFO (Back Flashover) pada isolator tower, dengan Persamaan:

$$
V_{L}=i \times R \varepsilon+L \frac{d i}{d t}+V_{M}
$$

\subsection{Gangguan kilat pada menara}

Untuk menghitung gangguan kilat pada menara, yaitu gangguan karena lompatan api balik (back flashover), digunakan teori gelombang berjalan, dengan Persamaan (9):

2.4. Menghitung kemungkinan jumlah lompatan api

$$
V_{50 \%} \mu \text { det }=\left(K_{1}+\frac{K_{2}}{\varepsilon 0.75}\right) \times 10^{3} k
$$

Menghitung Impedansi Surja Kawat Tanah dan Faktor Gandengan Radius korona kawat tanah :

$$
R \ln \left(\frac{2 h}{R}\right)=\frac{V}{E_{o}}
$$

2.5. Impedansi surja satu kawat tanah :

$$
Z_{11}=Z_{22}=60 \sqrt{\ln \frac{2 h}{r} \ln \frac{2 h}{R}}
$$

Koefisien pantulan pada dasar menara untuk $R$

$$
d=\frac{R-Z_{t}}{R+Z_{t}}
$$

Tabel 2. Salah satu data tower dan resistansi pentanahan pada tragi Bulukumba GI Sugguhminasa GI Tallasa

\begin{tabular}{llc}
\hline No & Tower & Pentanahan $(\mathbf{O h m})=\mathbf{R} \boldsymbol{\varepsilon}$ \\
\hline 1 & T. 39 & 5.4 \\
2 & T. 40 & 5.3 \\
3 & T. 46 & 4.6 \\
4 & T. 112 & 0.8 \\
5 & T. 114 & 0.6 \\
6 & T.113 & 0.4 \\
\hline
\end{tabular}

\subsection{Tegangan pada isolator}

Perhitungan ini dilakukan untuk semua besar arus kilat yaitu $60 \mathrm{kA}$ dan muka gelombang kilat yang diberikan $1 \mu$.

$V i=e_{o}\left\{(1-K) T+d\left[\left\{T-2\left(\frac{h_{t}}{c}-\frac{x_{1}}{c}\right)\right\}+\right.\right.$

$\left.(b-K a)\left(T-\frac{2 h_{t}}{c}\right)\right]+d^{2} b\left[\left\{T-2\left(\frac{2 h_{t}}{c}-\right.\right.\right.$

$\left.\left.\left.\frac{x 1}{c}\right)\right\}+(b-K a)\left(T-\frac{2 h_{t}}{c}\right)\right]+d^{3} b[\{T-$

$$
\left.\left.\left.2\left(\frac{3 h_{t}}{c}-\frac{x_{1}}{c}\right)\right\}+(b-K a)\left(T-\frac{6 h_{t}}{c}\right)\right]\right\}
$$


Implementasi sistem pentanahan ini dilakukan pada tower SUTT $150 \mathrm{kV}$ antara gardu Sungguminasa dengan gardu induk Tallasa tepatnya pada tower 39 yang berlokasi kecamatan Pallangga yang dilaksanakan pada tanggal 4 Mei 2017. Dalam implementasi sistem paralelisasi pentanahan ini menanam 2 batang tembaga pada jarak 2 meter dari masing- masing kaki tower $\mathrm{A}$ dan $\mathrm{C}$ dengan penambahan arang dan garam. Pemberian arang dan garam diturunkan bertahap seperti terlihat pada Gambar 1 di lakukan pengukuran paralelisasi.

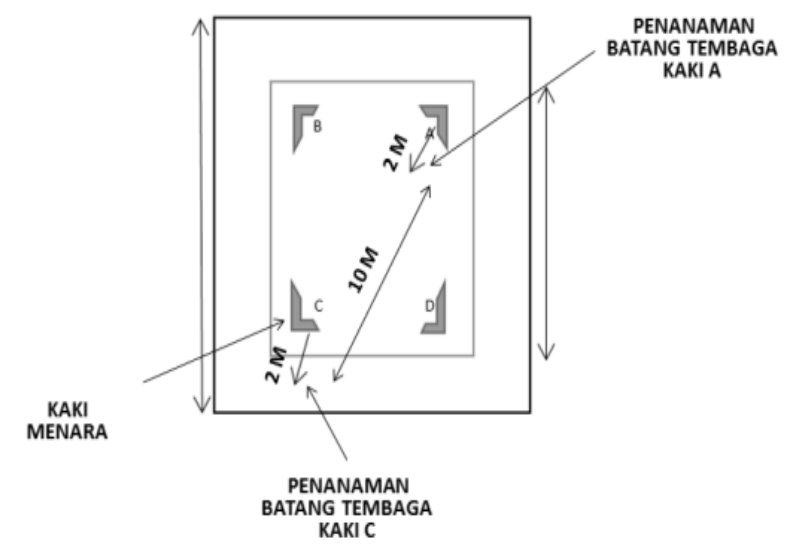

Gambar 1. Konstruksi pentanahan menara transmisi $150 \mathrm{kV}$ (tampak atas)

Tahanan kaki menara 10 Ohm dapat diperoleh dengan menggunakan satu atau lebih batang pengetanahan (ground rod) dan atau sistem counterpoise. Penambahan counterpoise dikombinasikan dengan efek air laut yang dapat membantu mengurangi kenaikan tegangan serta meningkat tahanan pentanahan di masingmasing menara [10]. Pemilihan penggunaan batang pengetanahan dan/atau sistem counterpoise tergantung dari tahanan jenis tanah di mana menara transmisi tersebut berada. Menggunakan satu batang pengtanahan tahanan kaki menara dihitung dengan menggunakan Persamaan sebagai berikut [11] :

$$
R=(\rho / 2 \pi L) \ln (2 L / d)-1
$$

Pengukuran 2 Batang Konduktor Tembaga Dengan Model Paralelisasi Harga A adalah kelipatan batang pengtanahan, dua batang diletakkan di mana saja. di beri garam, ke tiga beri [11].

$$
A=\sqrt{a r}
$$

Jenis-jenis tanah.

Tabel 3. Tahanan jenis tanah

\begin{tabular}{ccc}
\hline No & Jenis Tanah & $\begin{array}{c}\text { Tahanan Jenis } \\
(\text { ohm.m) }\end{array}$ \\
\hline 1 & Tanah Rawa & 10 s.d. 40 \\
2 & $\begin{array}{c}\text { Tanah liat dan } \\
\text { lading }\end{array}$ & 20 s.d. 100 \\
3 & Pasir basah & 50 s.d 200 \\
4 & Kerikil basah & 200 s.d. 3000 \\
5 & $\begin{array}{c}\text { Pasir dan kerikil } \\
\text { kering }\end{array}$ & $<10.000$ \\
6 & Tanah berbatu & 2000 s.d. 3000 \\
7 & Air laut dan tawar & 10 s.d. 100 \\
\hline Sumber : PUIL 2000 &
\end{tabular}

\section{Hasil dan Pembahasan}

\subsection{Hasil Penelitian}

Dalam analisis BFOR, perhatian khusus diberikan pada pengaruh yang berasal dari karakteristik penyatuan isolator flashover dan statistik petir. Model dapat diterapkan ke saluran transmisi secara keseluruhan atau sebagian dari propertinya, misalnya Beberapa menara pertama yang berasal dari gardu induk atau beberapa menara yang melintasi tebing gunung [12]. Model analisa disaluran transmisi $150 \mathrm{kV}$ khususnya di sepanjang line transmisi terdapat 81 tower berjarak 26,43 $\mathrm{km}$ pada GI Sungguminasa dan GI Tallasa. Pemodelan single diagram Tragi Bulukumba pada ATPDraw. Tabel 4 adalah Hasil Perhitungan Kapasitas Trafo pada Line Transmisi Sungguminasa -Tallasa

Tabel 4. Kapasitas trafo yang terpasang pada gardu induk

\begin{tabular}{cccccc}
\hline No & $\begin{array}{c}\text { S } \\
\text { (MVA) }\end{array}$ & $\begin{array}{c}\text { P } \\
\text { (MW) }\end{array}$ & $\begin{array}{c}\text { Q } \\
\text { (MVAR) }\end{array}$ & $\begin{array}{c}\text { R } \\
\text { (Ohm) }\end{array}$ & $\begin{array}{c}\text { L } \\
\text { (mH) }\end{array}$ \\
\hline 1 & 46 & 37 & 27,72 & 18,745 & 79,597 \\
2 & 12 & 10 & 7,44 & 69,841 & 296,564 \\
3 & 16 & 13 & 9,54 & 54,467 & 231,282 \\
\hline
\end{tabular}




\begin{tabular}{cccccc}
\hline No & $\begin{array}{c}\text { S } \\
\text { (MVA) }\end{array}$ & $\begin{array}{c}\mathbf{P} \\
\text { (MW) }\end{array}$ & $\begin{array}{c}\mathbf{Q} \\
\text { (MVAR) }\end{array}$ & $\begin{array}{c}\mathbf{R} \\
(\mathbf{O h m})\end{array}$ & $\begin{array}{c}\mathbf{L} \\
(\mathbf{m H})\end{array}$ \\
\hline 4 & 8 & 7 & 5,04 & 103,098 & 437,785 \\
5 & 12 & 9 & 7,02 & 74,019 & 314,307 \\
6 & 17 & 14 & 10,44 & 49,772 & 211,344 \\
& 26 & 20 & 15,3 & 33,962 & 144,211 \\
\hline
\end{tabular}

- Pemodelan single diagram Tragi Bulukumba yang menghubungkan GI Sungguminasa - GI Tallasa

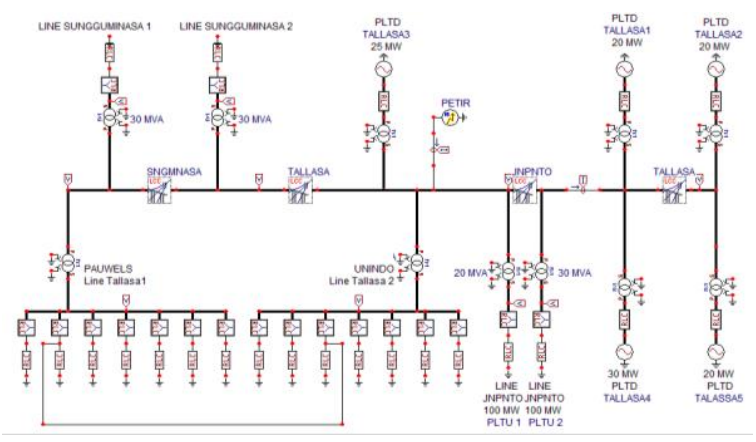

Gambar 2. Model simulasi single diagram tragi Bulukumba yang menghubungkan GI Sungguminasa GI Tallasa setelah terjadi sambaran petir

Bentuk hasil simulasi gelombang waktu muka dan waktu ekor petir adalah $0.15 \mathrm{~s}$ atau $1 / 50 \mu$ s. nilai arus puncak petir mencapai 359,89 MA, sehingga terjadi gangguan pada sistem kelistrikan yang mengakibatkan timbulnya tegangan impuls pada busbar dan back flash over (BFO), Kinerja backflashover diperkirakan dengan beberapa model flashover. Mereka tampil berbeda tergantung pada bentuk gelombang petir dan menara yang diteliti [13].

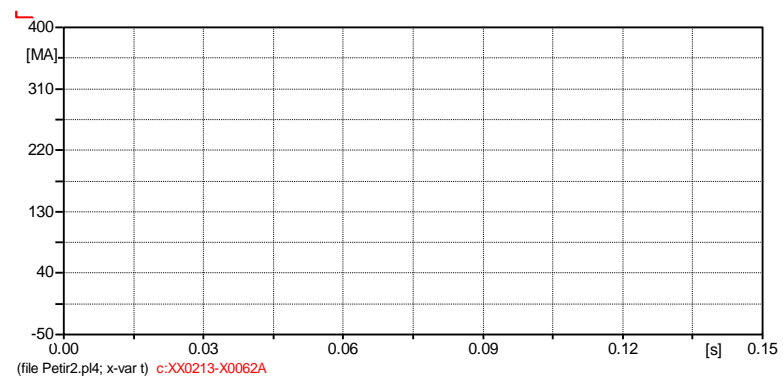

Gambar 3. Model Dari Arus Petir Tipe Heidler
- Analisis dampak terjadinya back flashover (BFO) yang mempengaruhi saluran transmisi 150 kV GI Sungguminasa - GI Tallasa akibat sambaran petir

Dari hasil simulasi untuk arus pada Saluran Transmisi $150 \mathrm{kV}$ GI Sungguminasa - GI Tallasa adalah sebesar 22,65 kA dan bentuk gelombang dalam waktu $\mathrm{T}=50 \mu \mathrm{s}$.

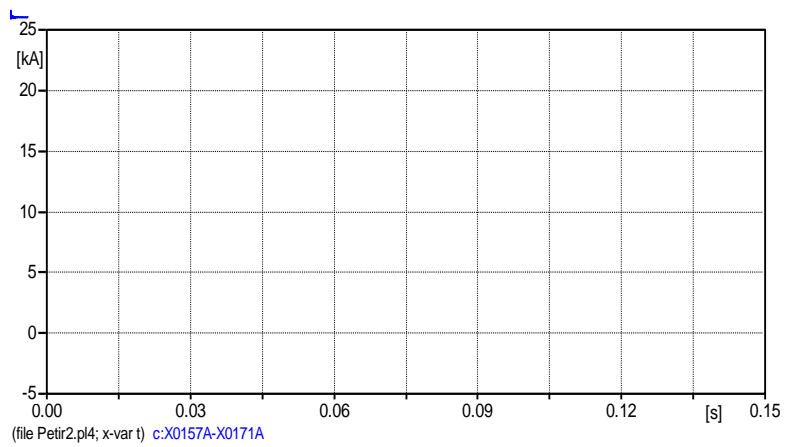

Gambar 4. Arus pada sistem kelistrikan line tragi Bulukumba

Tabel 5 merupakan data tower dan resistansi pentanahan pada tragi Bulukumba membawahi GI Sungguminasa, GI Takalar, GI Jeneponto dan GI Bulukumba yang terinterkoneksi terdapat beberapa tower yang mempunyai nilai resistansi pentanahan yang besar sehingga dapat berdampak terjadinya (BFO) Analisis dampak tejadinya $\mathrm{BFO}$ di dapatkan hasil peling tertinggi yaitu $1042,31 \mathrm{kV}$ berada pada tower 39 .

Tabel 5. Data tower dan besar resistansi pentanahan yang mengakibatkan terjadinya BFO

\begin{tabular}{cccc}
\hline No & Tower & $\begin{array}{c}\text { Pentanahan } \\
(\text { Ohm) }=\mathbf{R} \boldsymbol{\varepsilon}\end{array}$ & $\begin{array}{c}\text { Hasil } \\
\text { Pengukuran }(\mathbf{k V})\end{array}$ \\
\hline 1 & T.38 & 5.2 & 1037.78 \\
2 & T.39 & 5.4 & 1042.31 \\
3 & T.40 & 5.3 & 1040.05 \\
4 & T.41 & 5 & 1033.25 \\
5 & T.42 & 5 & 1033.25 \\
6 & T.43 & 5.2 & 1037.78 \\
7 & T.44 & 4.2 & 1015.13 \\
8 & T.45 & 4.4 & 1019.66 \\
9 & T.46 & 4.6 & 1024.19 \\
10 & T.47 & 4.6 & 1024.19 \\
11 & T.48 & 4.4 & 1019.66 \\
12 & T.49 & 4.4 & 1019.66 \\
13 & T.50 & 3.6 & 1001.54 \\
14 & T.51 & 3.6 & 1001.54 \\
15 & T.52 & 3.8 & 1006.07 \\
\hline
\end{tabular}




\begin{tabular}{cccc}
\hline No & Tower & $\begin{array}{c}\text { Pentanahan } \\
(\text { Ohm) }=\mathbf{R} \boldsymbol{\varepsilon}\end{array}$ & $\begin{array}{c}\text { Hasil } \\
\text { Pengukuran }(\mathbf{k V})\end{array}$ \\
\hline 16 & T.53 & 3.6 & 1001.54 \\
17 & T.60 & 3.6 & 1001.54 \\
18 & T.61 & 3.6 & 1001.54 \\
19 & T.62 & 3.8 & 1006.07 \\
20 & T.64 & 3.8 & 1006.07 \\
21 & T.65 & 3.8 & 1006.07 \\
22 & T.66 & 3.6 & 1001.54 \\
23 & T.68 & 3.6 & 1001.54 \\
24 & T.69 & 4.6 & 1024.19 \\
25 & T.70 & 4.6 & 1024.19 \\
26 & T.71 & 4.2 & 1015.13 \\
27 & T.72 & 4 & 1010.60 \\
28 & T.73 & 3.8 & 1006.07 \\
29 & T.74 & 3.8 & 1006.07 \\
30 & T.75 & 3.8 & 1006.07 \\
31 & T.76 & 4 & 1010.60 \\
32 & T.77 & 4.2 & 1015.13 \\
33 & T.78 & 3.8 & 1006.07 \\
34 & T.79 & 4.8 & 1028.72 \\
35 & T.80 & 4.6 & 1024.19 \\
36 & T.81 & 4.2 & 1015.13 \\
37 & T.82 & 4 & 1010.60 \\
38 & T.90 & 3.6 & 1001.54 \\
39 & T.93 & 3.6 & 1001.54 \\
40 & T.94 & 3.6 & 1001.54 \\
41 & T.96 & 3.6 & 1001.54 \\
42 & T.97 & 3.6 & 1001.54 \\
43 & T.99 & 3.8 & 1006.07 \\
44 & T.104 & 3.6 & 1001.54 \\
\hline & & &
\end{tabular}

- Analisis besar tegangan impuls pada saluran transmisi $150 \mathrm{kV}$ akibat back flashover (BFO)

Hasil simulasi Gambar 5 menunjukan nilai tegangan impuls akibat sambaran petir di GI Sungguminasa - GI Tallasa.

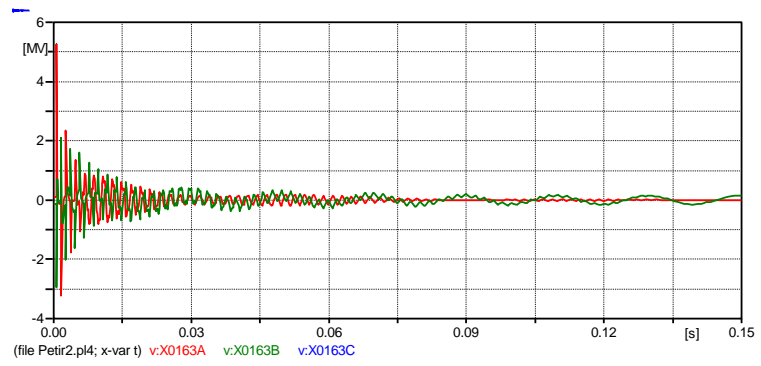

Gambar 5. Tegangan impuls akibat sambaran petir di line transmisi GI Sungguminasa - GI Tallasa

Hasil simulasi pada line tragi Bukulumba, arus petir yang terlalu tinggi sangat mempengaruhi tegangan pada sistem kelistrikan. Jadi peran penting dalam mengatasi sambaran petir adalah resistansi pentanahan pada setiap tower, rata-rata terdapat besar resistansi pentanahan pada beberapa tower sepanjang GI Sungguminasa - GI Tallasa sehingga tegangan back flashover (BFO) sangat berdampak terjadi gangguan pada sistem kelistrikan. Jadi kesimpulannya arus petir yang sangat tinggi pada sistem kelistrikan GI Sungguminasa - GI Tallasa membuat fasa $\mathrm{R}$ menjadi tidak stabil yaitu naik sebesar 5,271 MV kemudian pada masa peralihannya turun menjadi $190,59 \mathrm{kV}$ dan pada waktu ekor turun drastic menjadi $3595 \mathrm{~V}$. Arus puncak petir yang digunakan adalah arus simulasi sebesar 22,65 kA dan pentanahan sebesar $0,3 \mathrm{ohm}$ sehingga tegangan yang berada pada kawat fasa yaitu :

$$
\mathrm{V}=\frac{\mathrm{Z} .1}{2}=\frac{0.4 \Omega \cdot 22,65 \mathrm{kA}}{2}=4,530 \mathrm{MV}
$$

Tegangan impuls yang didapatkan dari perhitungan yaitu sebesar 5,271 MV mendekati dari hasil simulasi ATPDraw yaitu 4,530 MV. Jika dilihat dari hasil perhitungan tegangan impuls maka sudah melebihi BIL isolator yaitu $750 \mathrm{kV}$. Hal ini menunjukan bahwa akan menyebabkan flashover, sehingga merambat pada ke dua arah yang berlawanan pada saluran menuju GI ke kedua sisi line transmisi. sehingga relay akan berkerja membaca gangguan dan mentrip PMT/ CB di kedua sisi gardu induk.

- Analisis dampak terjadinya gangguan kilat pada menara yang mengakibatkan gangguan back flaschover (BFO) dengan teori gelombang berjalan yang mempengaruhi saluran transmisi 150 kV GI Sungguhminasa - GI Tallasa akibat sambaran petir

Pada metode ini diasumsikan bahwa fasa yang paling bawah yang akan mengalami lompatan api paling dahulu akibat sambaran kilat pada menara. Pada perhitungan ini dilakukan sampai $1 \mu$ det karena pada waktu itu gelombang pantulan negatif dari menara yang berdekatan (panjang gawang rata-rata diambil 300 meter) sudah sampai pada menara yang disambar kilat 
dan gelombang ini akan memperkecil tegangan pada menara. Beberapa model telah diajukan untuk mewakili menara [14], [15], [16]. Yang paling sederhana satu didasarkan pada konduktor tunggal didistribusikan parameter. Menara gelombang impedansi nilai berkisar dari 100 sampai 300 ohms [17].

Saluran yang akan dihitung merupakan saluran yang dimiliki oleh PLN, yakni saluran Sungguminasa-Tallasa. Saluran ini merupakan saluran transmisi udara ganda $150 \mathrm{kV}$ dengan konfigurasi kawat dan menara seperti diberikan pada Gambar 6. Data-data kawat dan isolator adalah:

Radius kawat tanah: $0,45 \mathrm{~cm}$

Radius sub-konduktor kawat fasa: $\quad 1,45 \mathrm{~cm}$ Jumlah sub-konduktor: 2

Jarak antara subkonduktor: $45,7 \mathrm{~cm}$

Tinggi kawat tanah pada menara: $37,7 \mathrm{~m}$

Tinggi kawat fasa $\mathrm{C}$ atau A pada menara:

$25,5 \mathrm{~m}$

Besar andongan kawat tanah dan kawat fasa: $7 \mathrm{~cm}$ Panjang renteng isolator: $6,43 \mathrm{~m}$

Perhitungan ini akan melihat pengaruh besarnya tahanan pentanahan terhadap tegangan yang dihasilkan gangguan kilat pada isolator. Oleh karena itu akan digunakan beberapa nilai pentanahan yang didapatkan dari data PLN, yakni tahanan $5,4 \Omega, 5,3 \Omega, 4,6 \Omega, 0,8 \Omega, 0,6 \Omega$, dan $0,4 \Omega$. Perhitungan ini secara bertahap dan tahapannya ditunjukkan oleh nomor yang diberikan di depannya.

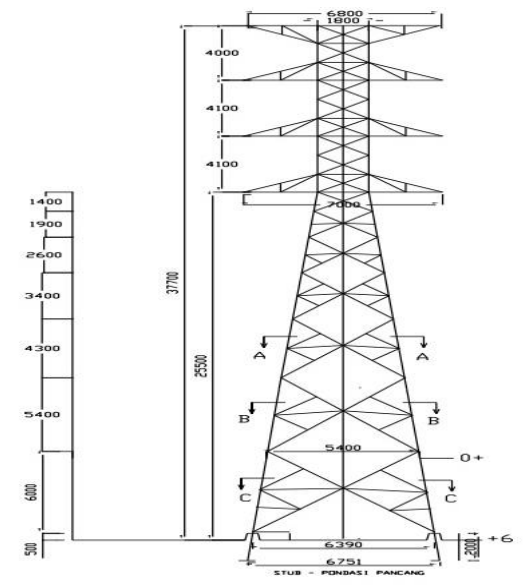

Gambar 6. Konfigurasi kawat dan menara
Tabel 6. Hasil-hasil perhitungan gangguan kilat pada Menara (perhitungan untuk fasa $\mathrm{C}$ atau $\mathrm{A}$ )

\begin{tabular}{ccccc}
\hline $\boldsymbol{T}$ & $\boldsymbol{I}_{\boldsymbol{o}}$ & $\boldsymbol{R}$ & $\boldsymbol{d}$ & $\boldsymbol{V}_{\boldsymbol{i}}(\mathbf{k V})$ \\
\hline $\boldsymbol{\mu d e t})$ & $(\mathbf{k A})$ & $(\boldsymbol{\Omega})$ & & \\
\hline & & 5,4 & $-0,937$ & 957,036 \\
& & 5,3 & $-0,938$ & 954,967 \\
1 & \multirow{2}{*}{60} & 4,6 & $-0,946$ & 937,819 \\
& & 0,8 & $-0,99$ & 842,694 \\
& & 0,6 & $-0,993$ & 838,454 \\
& & 0,4 & $-0,995$ & 834,238 \\
\hline
\end{tabular}

Dari hasil perhitungan nilai tegangan paling tertinggi berada pada tower 39. Koefisien pantulan adalah -0,937 dan tegangan pada isolator adalah 957,036 kV, semakin besar nilai pentanahan pada tower tersebut, maka akan memperbesar nilai koefisien pantul yang berarti kemungkin untuk terjadi back flashover juga akan semakin besar. Hal ini akan menyebabkan nilai tegangan pada isolator juga akan semakin besar. Oleh karena itu, upaya yang dilakukan berupa perbaikan nilai tahanan pentanahan kaki tower dengan membuat model paralelisasi batang pengetanahan dengan penambahan arang dan garam. Hal ini dimaksudkan untuk memperkecil nilai pentanahan kaki tower serta mempebanyak titik pembuangan petir. Penambahan titik pentanahan berdampak yang sangat maksimal.

- Pentanahan kaki menara dan analisis pengetanahan dua batang tembaga di menara transmisi $150 \quad \mathrm{kV} \quad$ GI Sungguhminasa - GI Tallasa pada Tower 39.

Perlindungan saluran transmisi terhadap gangguan petir menggunakan kawat tanah pada kaki menara untuk mengurangi resistansi kaki menara, Untuk memperoleh tahanan kaki menara kurang dari $5 \mathrm{ohm}$. Maka dilakukan penerapan pentanahan 2 batang tembaga dengan metode paralelisasi dengan penambahan arang dan garam, dengan jarak pentanahan dua meter dari kaki tower A dan C seperti Gambar 1. Pemasangan tembaga dilakukan di tower yang berbentuk bujur sangkar pada sisi $10 \mathrm{~m}$. Dua Batang tembaga dipasang ditanam sedalam 420 $\mathrm{cm}$ dari kaki menara $\mathrm{A}$ dan $\mathrm{C}$ dihubungkan menggunakan kawat BC $50 \mathrm{~mm}$ di kopel pada kaki tower, jenis tanah tower 39 adalah tanah 
pasir basah. Hasil uji lapangan korosi di Polandia menunjukkan bukti adanya perlindungan korosi yang lebih baik oleh elektroda tembaga berlapis baja bumi dibandingkan dengan seng lapisan dibuat menggunakan teknologi yang berbeda [18].

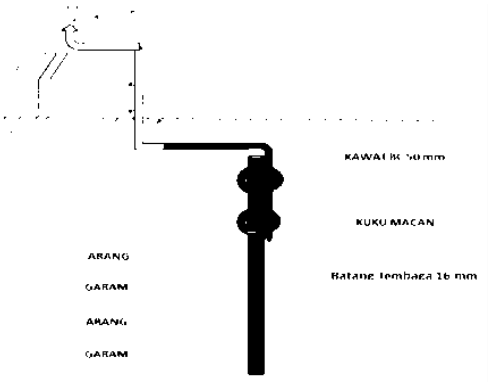

Gambar 7. Memperlihatkan ground rod pentanahan dari samping

Tabel 7. Hasil pengukuran pentanahan pada tower transmisi 39

\begin{tabular}{|c|c|c|c|c|c|}
\hline Data PLN & $\begin{array}{r}\text { Kaki to } \\
\text { tembaga ar: }\end{array}$ & $\begin{array}{l}\text { (tanpa } \\
\text { dan garam) }\end{array}$ & $\begin{array}{r}\text { Pentanah } \\
\text { (menara }\end{array}$ & $\begin{array}{l}1 \text { tembaga } \\
\text { rhubung) }\end{array}$ & $\begin{array}{l}\text { Paralelisasi Menara terhubung } \\
\text { penambahan arang dan garam }\end{array}$ \\
\hline \multirow[t]{2}{*}{$5 \mathrm{ohm}$} & $\begin{array}{c}\text { Kaki tower } \\
\text { A }\end{array}$ & $\begin{array}{l}\text { Kaki tower } \\
\text { B }\end{array}$ & $\begin{array}{l}\text { Kaki tower } \\
\text { A }\end{array}$ & $\begin{array}{l}\text { Kaki tower } \\
\text { B }\end{array}$ & Kaki tower A dan B \\
\hline & $12,22 \mathrm{ohm}$ & $9,97 \mathrm{ohm}$ & $1,24 \mathrm{ohm}$ & $1,74 \mathrm{ohm}$ & $0,78 \mathrm{ohm}$ \\
\hline
\end{tabular}

Tabel 8. Hasil perhitungan batang pengetanahan

\begin{tabular}{cc}
\hline $\mathbf{1}$ batang tembaga & 2 batang tembaga \\
\hline $2,6071 \Omega$ & $0,0864 \Omega$ \\
\hline
\end{tabular}

Hasil perhitungan dua buah batang tembaga dengan model paralelisasi yang ditanam tegak lurus kedalam tanah adalah 0,0864 Ohm. Jadi perhitungan telah memenuhi persyaratan yang berlaku yaitu dibawah $5 \mathrm{Ohm}$. Hasil penelitian ini menunjukan bahwa konfigurasi pengetanahan elektroda batang dengan penambahan arang dan garam yaitu 0,78 mampu mereduksi besarnya tahanan pentanahan, artinya semakin banyaknya elektroda ditanam dalam tanah maka semakin kecil nilai resistansi pentanahan, semakin panjang tembaga pentanahan ke tanah menyentuh air maka semakin bagus penurunan nilai pentanahannya, dan penambahan arang dan garam mempengaruhi penurunan nilai pentanahan karna arang dan garam mengandung zat-zat kimia dalam tanah terutama sejumlah zat organic maupun anorganik yang dapat larut perlu untuk diperhatikan. Untuk memperoleh penurunan resistansi pentanahan yang efektif yaitu dengan mentanahkan tembaga lebih dalam sampai mencapai dimana larutan garam dan arang terkena air atau keadaan basah. Tujuan memperkecil nilai resistansi pentanahan kaki tower serta mempebanyak titik pembuangan petir, agar kontinuitas pelayanan listrik tidak terjadi blackout pada saat musim penghujan akibat sambaran petir dan dapat melindungi peralatan transmisi $150 \mathrm{kV}$ GI Sungguhminasa GI Tallasa.

\section{Kesimpulan}

Penelitian ini menampilkan nilai resistansi pentanahan tinggi pada jaringan transmisi 150 kV Gi Sungguminasa - GI Tallasa saat terkena sambaran petir dapat membuat jaringan kelistrikan menjadi tidak stabil. Dengan penerapan metode paralelisasi yang telah dilakukan di lapangan dapat menurunkan nilai pentanahan mampu menghindari terjadinya back flashover Pemasangan ini tujuan memperkecil nilai pentanahan kaki tower serta mempebanyak titik pembuangan petir, agar kontinuitas pelayanan listrik tidak terjadi black out pada saat musim penghujan akibat sambaran petir dan dapat melindungi peralatan transmisi $150 \mathrm{kV}$ GI Sungguminasa - GI Tallasa. Diharapkan penelitian kandungan penggunaan arang perlu penelitian lebih lanjut terhadap pengaruh tiap jenis-jenis tanah

\section{Referensi}

[1] Z. Reynaldo, P. Y. Eko, 10 October 2008, Lightning Performance of Extra High Voltage $500 \mathrm{Kv}$ Lines at East Java - Indonesia, IPTEK, The Journal for 
Technology and Science, Vol. 19, No. 4, November 2008, 100.

[2] J.A Martinez, Member, IEE, and F Castro-Aranda, 2003, Lightning Performance Analysis of Transmission Lines Using the EMTP, Barcelona, Spain, IEEE, 300.

[3] P. Sarajcev, J. Vasilj, D. Jakus, 2015, Method for estimating backlashover rates on $H V$ transmissions lines based on EMTP-ATP and curve of limiting parameters, University of Split, FESB, Dapartment of Power Engineering, R. Boskovica 32, HR-21000 Split, Croatia, Elsevier, Electrical Power and Energy systems 78 (2016) 127-137, 129.

[4] S. W. Georges, Member, IEEE, F. H. Slaoui, P. J. Lagace, Member, IEEE, X. D. Do, Senior Member, IEEE and J. Forth, Member, IEEE, 2003, Evaluation of Grounding System Impedance of a Near Sea Water HV Electric Power Installation, 1591.

[5] I. Janardana. Perbedaan Penambahan Garam Dengan Penambahan Bentonit Terhadap nilai Tahanan Pentanahan Pada Sistem Pentanahan, VOL, 4 No. 1 Januari - Juni 2005, 24.

[6] IEEE WG, 1996, Modeling guidelines for fast front transients. IEEE Trans. Power Deliv. 11 (1) (1996) 493-506.

[7] H.W. Dommel, 1986, Electromagnetic Transients Program, Portland, Reference Manual, Bonneville Power Administration.

[8] ]L. Prikler, H.K. Hoidalen, 2009, ATPDRAW version 5.6 for Windows 9x/NT/2000/XP/Vista: User's Manual, Norwegian University of Technology. Trondheim, Norway.

[9] T.S. Hutauruk, 1991, Gelombang Berjalan Dan Proteksi Surja, Jakarta, Erlangga, 132.
[10] S. Georges, F. Slaoui, P. J. LagacC X.D. Do, Senior Member IEEE J. Fortin, Member IEEE, 1999 IEEE , Evaluation of The Effect Of Salt Water And A Counterpoise On The Voltage Profile Of A HV Power Transmissions Line Grounding System In A Two Layer With High Resistivity Soil, Montreal, Canada, , 1020.

[11] T.S. Hutauruk, 1991, Pengetanahan Netral Sistem Tenaga Dan Pengetanahan Peralatan. Jakarta, Erlangga, 141.

[12] Sarajcev Petar, 12 May 2014,Monte Carlo method for estimating back flashover rates on high voltage transmission lines.University of Split, FESB, Dapartment of Power Engineering, R. Boskovica 32, HR-21000 Split, Croatia, Elsevier, Electric Power Systems Research 119 (2015) 247-257.

[13] Mackow, A., Kizilcay, M, Mitigation methods to improve the lightning performance of hybrid transmission line. Sigen, Germany, The work was supported by German TSO, Amprion.

[14] W.A. Chisholm and Y.L. Chow, September 1983, I Lightning surge response of transmission towers, $\mathrm{i}$ IEEE Trans, on Power Apparatus and Systems, vol. 102, nc. 9 , pp. 3232-3242.

[15] M. Ishii et al, July 1991, $i$ Multistory transmission tower model for lightning surge analysis, i IEEE Trans, on Power Delivery, vol. 6, no. 3, pp. 1327-1335.

[16] A.R. Hileman, 1999, Insulation Coordination for Power Systems, Marcel Dekker.

[17] A. Imece, Chairman, January 1996, I Modeling guidelines for fast transients, IEEE Trans, on Power Delivery, vol. 11, no. 1.

[18] M. Robert, L. Marek, N. Radoslaw, 2010, Influence of Climatic Conditions in China on Reliability of Power Earthing System, IEEE, 1546. 